\title{
Vascular Function and Inflammation in Rheumatoid Arthritis: the Role of Physical Activity
}

\author{
George S. Metsios ${ }^{1,2, *}$, Antonios Stavropoulos-Kalinoglou ${ }^{1,2}$, Aamer Sandoo ${ }^{2}$, Jet J.C.S. Veldhuijzen \\ van Zanten ${ }^{2}$, Tracey E. Toms ${ }^{2}$, Holly John ${ }^{2}$ and George D. Kitas ${ }^{2}$ \\ ${ }^{I}$ School of Sport Performing Arts and Leisure, University of Wolverhampton, Walsall, West Midlands, United Kingdom \\ ${ }^{2}$ Department of Rheumatology, Dudley Group of Hospitals NHS, Foundation Trust, Russell's Hall Hospital, Dudley, \\ West Midlands, United Kingdom
}

\begin{abstract}
Inflammation disturbs biochemical pathways involved in homeostasis of the endothelium. Research has established clear links between inflammatory mediators, particularly C-reactive protein and tumour necrosis factor alpha, endothelial dysfunction, and atherosclerosis. Endothelial dysfunction and atherosclerosis may be subclinical at early stages, and thus the ability to detect them with non-invasive techniques is crucially important, particularly in populations at increased risk for cardiovascular disease, such as those with rheumatoid arthritis. This may allow the identification of interventions that may reverse these processes early on. One of the best non-pharmacological interventions that may achieve this is physical activity. This review explores the associations between inflammation, endothelial dysfunction, and atherosclerosis and discusses the role of exercise in blocking specific pathways in the inflammation, endothelial dysfunction - atherosclerosis network.
\end{abstract}

Keywords: Inflammation, Atherosclerosis, Endothelial function, Cytokines, Vascular function, Exercise, Physical activity, Cardiovascular disease.

\section{INTRODUCTION}

The endothelium is now regarded as a dynamic organ lining the entire vascular system. It is responsible for many atheroprotective functions via its regulation of the immune response, fibrinolysis, coagulation, as well as multiple other functions related to vascular growth, vasoprotection, and vasoregulation. Disruption of normal endothelial function impedes its protective effects on vascular homeostasis, an early event characterizing the development of cardiovascular disease (CVD) [1-3]. Most importantly, endothelial dysfunction and the early stages of CVD may occur in the absence of any clinical symptoms. Hence, finding methods for assessing vascular dysfunction during the early stages of the disease is important, particularly in patient groups at high CVD risk [4].

Rheumatoid arthritis (RA) is the most common chronic inflammatory arthritis characterized by symptoms and signs of joint and systemic inflammation, joint destruction, body composition alterations, and physical disability. It also associates with high CVD morbidity and mortality, which are not fully explained by the presence of traditional CVD risk factors [5-8]. In RA, increased local (synovial) and systemic expression of specific inflammatory mediators may have detrimental effects on the endothelium by enhancing biochemical processes leading to its dysfunction and eventually

*Address correspondence to this author at the School of Sport Performing Arts and Leisure, University of Wolverhampton, Wolverhampton, West Midlands, United Kingdom; Tel: +44-0121-4561302;

E-mail: G.Metsios@wlv.ac.uk the development of atherosclerosis [2, 9]. Indeed, the inflammatory pathways involved in the pathogenesis of RA and atherosclerosis share many characteristics [10]. Inflammation in RA is often evaluated by measuring the acute phase reactant C-reactive protein (CRP) and/or the erythrocyte sedimentation rate (ESR), which, in combination with other clinical markers (e.g. disease activity or X-ray scores), are used to assess the disease state and response to treatment [11]. The acute phase response is attributed to increased levels of pro-inflammatory cytokines, such as tumour necrosis factor alpha (TNF-alpha) and interleukin-6 (IL-6) [10], which are individually or synergistically involved in many other disease processes, including joint destruction [12] altered body composition [13], and changes in vascular homeostasis $[14,15]$.

\section{INFLAMMATION AND ENDOTHELIAL DYSFUNC- TION}

The endothelium controls vascular function by releasing vasoactive factors such as nitric oxide (NO), prostacyclin $\left(\mathrm{PGI}_{2}\right)$, and endothelin-1 (ET-1). Endothelial dysfunction occurs when the balance between these vasoactive factors is disturbed. The down-regulation of endothelial NO synthase (eNOS) plays an important role in this process [16]. Altered endothelial homeostasis due to the disturbed NO production is characterized by diminished endothelium-dependent dilation and increased expression of adhesion molecules, as well as changes in endothelial cell phenotype and increased endothelial permeability [17]. Such changes in the structure and function of the endothelium are thought to be important as 
initial stages in the pathogenesis of atherosclerosis and CVD [18].

Several studies have established a strong link between inflammation and endothelial dysfunction. In vitro, CRP modulates eNOS activity of human endothelial cells $[19,20]$ via uncoupling eNOS and subsequently increasing superoxide anions (oxidative stress) from NADPH oxidase [21]. As a result, phosphorylation of eNOS is decreased, and this subsequently reduces bioavailability of NO [22]. Apart from NO, CRP upregulates the expression of ET-1 which is a vasoconstrictor [23]. Studies also reveal a direct effect of TNF-alpha on dowregulating the expression of eNOS and diminishing endothelial NO [15]. TNF-alpha downregulates at the same time enzymatic activities of eNOS and argininosuccinate synthetase (regulator of citrulline/NO cycle) [24] and induces an increase in mRNA degradation of both eNOS and neuronal NO synthase promoting vasoconstriction [25]. In addition, by activating NADPH oxidase, TNF-alpha stimulates the generation of reactive oxygen species within the endothelial environment further impairing NO-mediated vasodilation [26]. Apart from inhibition of NO production, TNF-alpha may also be responsible for the reduction in the bioavailability of NO [27]. This is perhaps the main reason why TNF-alpha inhibition is directly linked to improved endothelial function in both RA [28] and non-RA populations [29].

Endothelial function and morphology are reported to be significantly worse in RA compared to healthy controls and this is attributed in large part to the high-grade inflammatory state of RA [30, 31]; in fact, acute inflammation (e.g. in response to immunization) and low-grade chronic systemic inflammation (detected using high sensitivity CRP assays) in healthy individuals has been directly linked with arterial stiffness and vascular dysfunction $[32,33]$. However, despite this biologically plausible link between inflammation and vascular dysfunction, there are still some controversies and inconsistent results in RA [34,35], where some studies report a lack of association between systemic inflammatory load and endothelial function [36-38]. This may be attributed to different methodological approaches (e.g. using small, diverse patient populations cross-sectionally, or even smaller populations longitudinally but with short time courses), or lack of sufficient statistical power and no correction for multiple potential confounders (e.g. age and many CVD risk factors). The link between inflammation and vascular function appears to be more consistently demonstrated in homogeneous RA samples, such as young patients, patients with new onset RA and without established CVD [31, 39]. Vascular function may progressively deteriorate during the course of RA [40]. Hence, RA patients with long disease duration may already have significantly impaired endothelial function at the time of assessment, irrespective of disease "current" activity. Given the fluctuations in inflammation characteristic of RA, it might be that longstanding, though intermittent, inflammatory insult to the endothelium is of more importance to vascular function in RA than the current level of inflammation [41]. Studies that took into account long-term inflammatory burden have been able to demonstrate associations between this and vascular function $[36,39]$.

\section{INFLAMMATION AND ATHEROSCLEROSIS}

Endothelial cell dysfunction, evident as NO deficiency, appears to be amongst the earliest processes involved in atherosclerosis. Reduction of NO bioavailability disrupts the balance of the vasoactive factors, which allow ET-1 levels to increase and cause vasoconstriction [16]. Along with the biochemical mediators of endothelial function, mechanical forces and in particular, shear stress are also responsible for altering the phenotype of endothelial cells. Shear stress is the tangential stress that is applied to the artery wall and induces distension of the arteries; it is long-known that atherosclerotic lesions originate mainly in areas of low shear stress, where flow is disturbed $[42,43]$. In these areas, endothelial cells promote a pro-atherogenic phenotype [44], enhancing both the local selectivity of plaque formation, as well as vessel wall remodeling, which, in turn, affects plaque vulnerability [45].

At the initial stages of atherosclerosis, leukocytes, particularly monocytes, progressively transmigrate through the endothelium with the help of monocyte chemoattractant protein 1 (MCP-1) and IL-8 [14]. Atherosclerosis progresses via the differentiation of monocytes into macrophages that retain low-density lipoproteins and become foam cells. Increased permeability of RA endothelial cells further enhances the entry of low-density lipoproteins and further promotes this cascade of events [46]. It has now been well-established that inflammation is involved in all phases of the atherothrombotic processes [2]. Whereas MCP-1 and IL-8 regulate monocyte transmigration, IL-8 can be upregulated in endothelial cells by CRP via the NF-kB pathway [47]. CRP can also increase the expression of macrophage colony stimulating factor (M-CSF), responsible for the differentiation of monocytes into macrophages. Subsequently, macrophage proliferation increases, thereby enhancing the progression of atherosclerosis via the promotion of the formation of foam cells [48]. An alternative effect of CRP is to destabilize the atheromatous plaque at later stages of atherosclerosis, by upregulation of matrix metalloproteinases [49] which causes weakening of the plaque's, fibrous cap. Apart from the above effects of CRP on these individual steps of atherosclerosis, it also enhances fibrinolytic procedures within the endothelial environment. CRP increases plasminogen activator inhibitor-1 mRNA through induction of the NF-kB signalling pathway [50] and downregulates endothelial tissue plasminogen activator, a serine protease that is responsible for fibrinolysis. This biochemical process is orchestrated by TNF-alpha and IL-1b [51]. Other important atherogenic properties of CRP include CRP-induced oxidative stress via overproduction of reactive oxygen species [52]. Reactive oxygen species in the endothelium enhance degradation of eNOS via eNOS uncoupling and subsequent increase in superoxide [53]. In general, superoxide reacts rapidly with NO, forming peroxynitrite which significantly impairs NO bioactivity [54] and deteriorates endothelial function.

TNF-alpha has direct effects on endothelial permeability by altering the distribution of endothelial cadherin-catenin and inhibiting the re-structure of F-actin fibers [55]. This procedure may enable monocyte transmigration into the endothelium and amplify the cascade of procedures that favor the formation of foam cells from macrophages [54]. Fur- 
thermore, the proliferation of macrophages and increased formation of foam cells enhances secretion of TNF-alpha in the endothelium, perpetuating this vicious atherogenic cycle [3]. TNF-alpha also upregulates membrane expression of vascular cell adhesion molecule-1 [56], which plays a well established role in atherosclerosis [57] and it precedes the development of thickened intima with foam cell lesions [58]. Apart from these in vitro observations, increased expression of serum TNF-alpha has been found in patients with atherosclerotic complications in population studies $[59,60]$. In RA patients, TNF-alpha enhances prothrombotic states such as dyslipidemia [61], but, most importantly, pooled evidence reveals that anti-TNF-alpha treatment may be in part responsible for reducing the risk for CVD events in RA [62]. Recent studies also reveal that TNF-alpha is involved in the more advanced processes of atherosclerosis, specific to formation of an advanced lesion via the inhibition of endothelial progenitor cells [63]. In RA patients, endothelial progenitor cell numbers are decreased compared to the healthy population [63], a phenomenon which reverses via blockade of TNF-alpha [64].

Inflammation in RA associates with dramatic increases of IL-6, IL-1 and TNF-alpha levels, which can trigger the acute-phase response resulting in high CRP, and have direct effects on the endothelium that may enhance atherosclerotic processes. As such, uncontrolled inflammation is thought to be amongst the prime factors involved in the accelerated atherosclerosis in RA [1,2].

\section{THE EFFECTS OF EXERCISE ON VASCULAR BIOLOGY}

Increasing physical activity has been identified as one of the most important non-pharmacological interventions in both preventing and rehabilitating patients with non- communicable chronic diseases such as CVD. This is because exercise reverses endothelial dysfunction and has important anti-atherogenenic and anti-inflammatory effects (Fig. 1). Most importantly, even compared to standardized interventional strategies, exercise may improve survival at lower treatment costs [65].

\section{Endothelial Function and Exercise}

Exercise exerts significant effects on the endothelial system, both acutely and in the long term. These stimuli intervene and beneficially modify endothelial cell phenotype [17]. The acute effects of exercise are characterized by significant increase in blood flow pertaining to the increased metabolic demands of the exercizing muscles and are closely related to the muscle fibre type recruitment (slow or fast twitch) as well as the duration and intensity of exercise [66]. The major mechanism responsible for exercise-induced hyperaemia is endothelial NO [67] and occurs due to the increased endothelial eNOS protein expression [68] as well as eNOS activation via Akt phosphorylation [69]. Exercise acutely increases local expression of endothelial progenitor cells (endothelial repair) as well as cultured/circulating angiogenic cells which promote angiogenesis and endothelial growth [70]. Shear stress which is the result of exerciseinduced blood flow enhances intracellular mechanisms which increase eNOS transcription and upregulate antioxidative mechanisms. Specifically, tyrosine kinase c-Src acts to increase eNOS and extracellular superoxide dismutase expression, both of which relate to better endothelial function [71]. In addition, it has been well-established that shear stress increases the expression of $\mathrm{PG}_{2}$, a vasodilator and inhibitor of platelet aggregation [72]. Furthermore, vascular endothelial growth factor, which regulates capillary supply and exercise-induced angiogenesis, is significantly increased in response to exercise in both untrained and

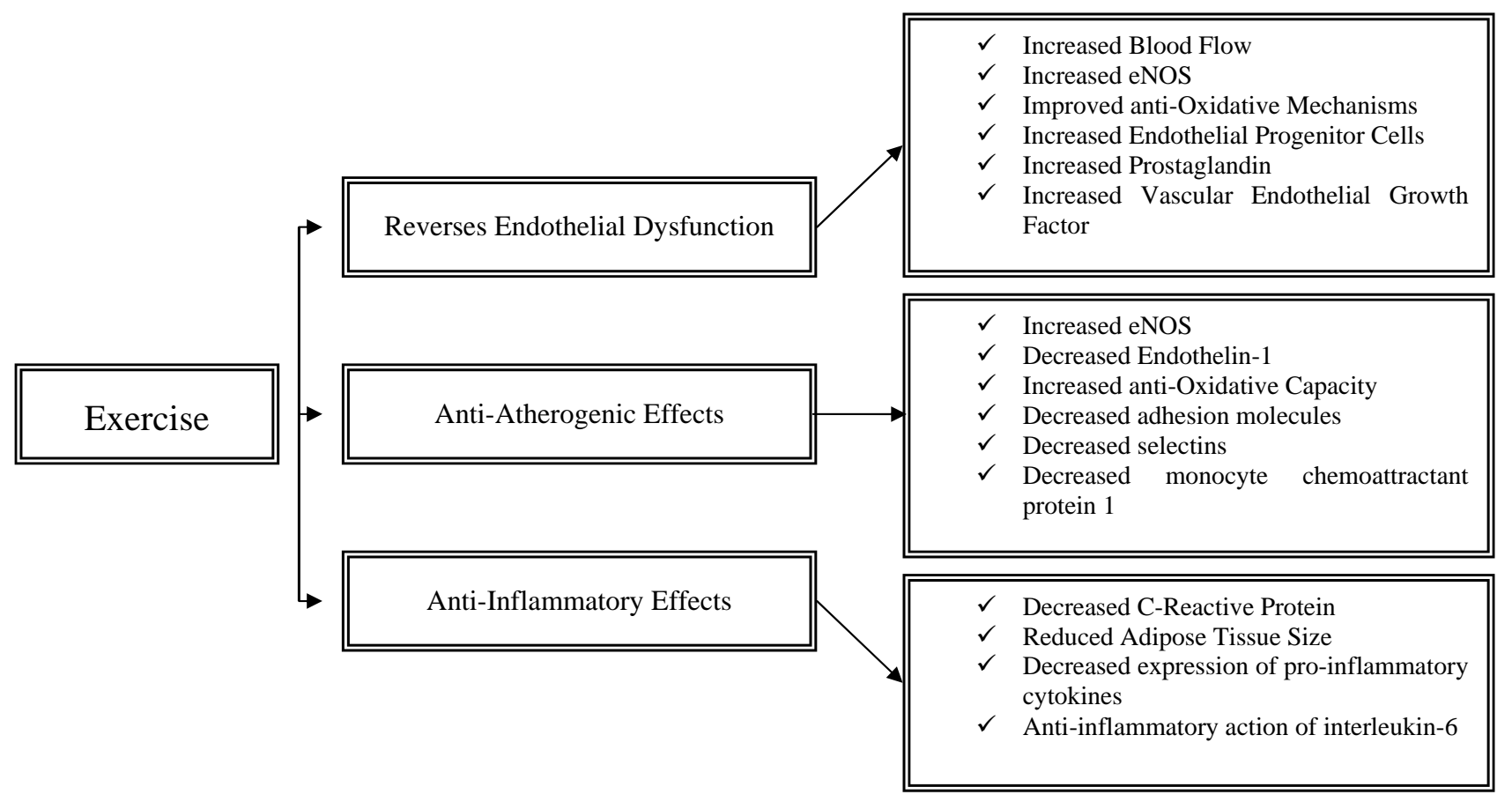

Fig. (1). The effects of physical activity on endothelial function, atherosclerosis and inflammation. 
trained individuals [73]. In the long term, the above mentioned physiological responses promote vascular remodelling, a necessary adaptation for improved oxygen exchange and blood flow delivery [74]. These long-term improvements are characterized by improved NO bioavailability and/or endothelium-dependent vasodilation that may even reverse age-related vascular deterioration [75, 76]. Improved endothelium-dependent vasodilation in response to long-term exercise is a consistent finding in both healthy [77] and disease populations [78].

\section{Anti-Atherogenic Effects of Exercise}

Acutely, due to exercise-induced shear stress, eNOS mRNA expression increases while ET-1 decreases [79, 80], while concomitant changes involve down-regulation of vascular cell adhesion molecule 1 [81]. Oxidative stress accelerates atherogenesis via oxidation of retained lowdensity lipoprotein, enhancing formation of foam cells [3]. An important long-term adaptation to exercise is the improvement in the anti-oxidative capacity of the human body, i.e. resistance to oxidative stress [82]. In particular, the enzymes catalase and superoxide dismutase which decompose reactive oxygen species are significantly increased as a result of habitual physical activity [83]. Increased eNOS in the endothelium increases anti-oxidant molecules such as superoxide dismutases 1 and 3 and angiotensin receptor type 2 and decreases oxidative molecules such as NADPH oxidase and angiotensin receptor type 1 [84]. Endothelial expression of adhesion molecules, selectins and MCP-1, all of which promote atherosclerosis, also decreases [85].

\section{Anti-Inflammatory Effects of Exercise}

Physical activity and/or moderate intensity exercise have profound anti-inflammatory effects in the healthy population as well as patients with chronic diseases [86]. In populationbased studies, regular physical activity is consistently associated with a reduction in CRP levels $[87,88]$ which is also the case in patients with RA [89, 90]. The exact mechanisms whereby regular exercise reduces CRP have not yet been fully elucidated, but it seems that this association may exist via exercise-induced reduction in hypertension, triglycerides, and apolipoproteins, factors which are directly related to CRP concentration [91]. Most importantly, exercise reduces adipose tissue which is largely responsible for secretion of IL-6, a major trigger for hepatic production of CRP [92, 93]. However, these are physiological responses of moderate physical activity/exercise, whereas strenuous exercise may acutely promote an inflammatory response. CRP may increase immediately after prolonged strenuous exercise but returns to basal levels after approximately 48 hours, while this proportionate rise in CRP depends on the intensity of the exercise and the subsequent exercise-induced muscle damage $[94,95]$.

Recent advances in muscle physiology reveal that muscle tissue is responsible for the production of myokines (muscle cytokines) suggesting that muscle is also an endocrine organ [96]. Muscle contractions regulate expression of specific cytokines such as IL-6, -8, -10, and -15, as well as IL-1 receptor antagonist and TNF-alpha [96-98]. It is thought that, although IL-6 is predominantly a pro-inflammatory cytokine, it may also have under certain circumstances anti-inflammatory properties [99]. In that light, and based on the fact that IL-6 increases exponentially with acute exercise up to 100 times compared to resting levels and returns to resting levels post-exercise [100], it has been suggested that IL-6 is the most important cytokine that induces the anti-inflammatory effects of exercise [96]. In contrast, pro-inflammatory cytokines IL-1b and TNF-alpha do not generally increase in response to moderate intensity exercise [101], whereas antiinflammatory cytokines such as IL-1ra and IL-10, significantly increase $[99,102]$. Interestingly, in response to regular exercise, IL-6 exerts its anti-inflammatory effects by primarily inhibiting the expression of TNF-alpha [99]. Data have demonstrated that IL-6 inhibits lipopolysacharideinduced TNF-alpha in human blood mononunclear cells [103], whereas TNF-alpha levels are overexpressed in IL-6 deficient mice [104]. Recently, the transcriptional coactivator PGC1a has also attracted attention as it suppresses various inflammatory responses and regulates the effects of exercise [105] by coactivating transcription factors involved in biogenesis of mitochondria, oxidative phosphorylation and fatty acid oxidation [106, 107]. All these biological changes in cytokine expression in response to exercise, lead to beneficial long-term effects. Indeed, a consistent finding in the literature is that regular exercise relates to decreased systemic inflammation in both healthy and diseased populations [88, 89, 108, 109].

\section{EFFECTS OF EXERCISE ON CVD IN RA}

The extensive damage of the joint structures in RA has initially led to the notion that RA patients should rest, as exercise may enhance joint damage [110]. However, during the last decade substantial evidence deriving from randomised trials reveals that exercise inhibits the progression of the disease and improves both wellbeing and functional ability of RA patients [90]. This is due to normal physiological processes which develop as a result of exercise training such as the improved muscle co-ordination and hypertrophy, reduced fat mass and better immune function. Patients that indeed have to refrain from specific exercises are those with extensive structural damage; in this occasion load of the damaged joints has to be avoided and can be replaced with alternative types of exercise. The beneficial effects of different exercise training types on disease activity and severity have been confirmed several times by various studies [110, 111] and hence, based on these evidence, exercise has now been incorporated in the management of RA [112]. It is, therefore imperative that RA patients embark on exercise training programmes. Although exercise is beneficial, increasing physical activity in this population may prove difficult [113] perhaps due to the frequent advice from rheumatology specialists to RA patients, that exercise may exacerbate disease symptoms [114]. However, data from published studies [110] of excellent quality as well as anecdotal evidence, reveal that RA patients should and can exercise at high intensities, and this is beneficial for various outcomes of this chronic disease. Moreover, studies have collectively shown that overall the adherence rates in exercise programmes can be high, presumably due to the fact that the significant improvements achieved via exercise promote self motivation [90]. 
In a systematic review on exercise, CVD and RA, we found that, surprisingly, no studies have investigated the effects of exercise on CVD outcomes in this population [90]. However, given the ample evidence of the beneficial effects of physical activity/exercise on inhibiting disease progression and improving disease outcomes, we have proposed a model in which exercise should be incorporated in the management of the disease in order to prevent CVD, which is highly prevalent in this population. In this model, we suggest that effective treatment and control of inflammation should precede involvement in exercise in order to prohibit further damage and discomfort for the RA patient. Various drugs are available for patients with RA, including biological agents such as TNF-alpha, which target different biological pathways for inhibiting disease progression. Overall, medication strategies are effective in ameliorating disease activity (i.e. reduced expression of pro-inflammatory cytokines and CRP), a phenomenon that is also apparent as a response to exercise training. Nevertheless, given the lack of evidence regarding the effects of exercise on RA, potential changes in medication should always be based on robust clinical outcomes and patient feedback.

Exercise involvement and/or increased physical activity are included in the management of many chronic diseases. In RA, where patients experience increased prevalence of CVD, exercise may be even more important due to its antiatherogenic and anti-inflammatory effects [17, 99]. The majority of studies on RA and exercise investigated the effects of physical activity/exercise regimens on improving RA-related disease outcomes. We have recently shown that physically inactive RA patients have worse CVD risk profile compared to physically active patients. In this cross-sectional study, we have investigated classical and novel risk factors, the prevalence of established CVD as well as the risk assessment of developing CVDs in physically active as well as inactive RA patients. Regarding the novel CVD risk factors, our results revealed that parameters associated with vascular function (e.g. von Willebrand factor), fibrinolysis atherogenesis (lipoproteins), pro-inflammatory cytokines, and CRP were markedly improved in patients who demonstrated increased levels of physical activity [89]. However, more research is required in order to investigate the potential associations of exercise on vascular function and CVD risk in this population as well as the mechanisms that underlie these associations.

\section{CONCLUSION}

Evidence from basic research supports a clear association between inflammation, vascular dysfunction and atherosclerosis. In RA, although evidence exists to support this association for atherosclerosis, the results are equivocal at least for endothelial dysfunction, potentially due to the differences in the methodological designs that do not take into account important factors that could influence endothelial function and atherosclerosis in RA. In addition, exercise has a protective effect via inhibiting the expression of inflammatory markers and their effects on both endothelial dysfunction and promotion of atherosclerosis. Future studies in RA should specifically investigate the effects of exercise regimes on endothelial function and atherosclerosis both in population studies and at a molecular level.

\section{REFERENCES}

[1] Libby P. Role of inflammation in atherosclerosis associated with rheumatoid arthritis. Am J Med 2008; 121: S21-31.

[2] Sattar N, McCarey DW, Capell H, McInnes IB. Explaining how "high-grade" systemic inflammation accelerates vascular risk in rheumatoid arthritis. Circulation 2003; 108: 2957-63.

[3] Lamon BD, Hajjar DP. Inflammation at the molecular interface of atherogenesis: an anthropological journey. Am J Pathol 2008; 173: 1253-64.

[4] Gonzalez MA, Selwyn AP. Endothelial function, inflammation, and prognosis in cardiovascular disease. Am J Med 2003; 115 (Suppl 8A): 99S-106S.

[5] Kitas GD and Erb N. Tackling ischaemic heart disease in rheumatoid arthritis. Rheumatology (Oxford) 2003; 42: 607-13.

[6] Douglas KM, Pace AV, Treharne GJ, et al. Excess recurrent cardiac events in rheumatoid arthritis patients with acute coronary syndrome. Ann Rheum Dis 2006; 65: 348-53.

[7] Panoulas VF, Douglas KM, Milionis HJ, et al. Prevalence and associations of hypertension and its control in patients with rheumatoid arthritis. Rheumatology (Oxford) 2007; 46: 147782.

[8] Panoulas VF, Metsios GS, Pace AV, et al. Hypertension in rheumatoid arthritis. Rheumatology (Oxford) 2008; 47: 1286-98.

[9] Stevens RJ, Douglas KM, Saratzis AN, Kitas GD. Inflammation and atherosclerosis in rheumatoid arthritis. Expert Rev Mol Med 2005; 7: 1-24.

[10] Brennan FM, McInnes IB. Evidence that cytokines play a role in rheumatoid arthritis. J Clin Invest 2008; 118: 3537-45.

[11] McInnes IB. Rheumatoid arthritis. From bench to bedside. Rheum Dis Clin North Am 2001; 27: 373-87.

[12] Choy EH, Panayi GS. Cytokine pathways and joint inflammation in rheumatoid arthritis. N Engl J Med 2001; 344: 907-16.

[13] Metsios GS, Stavropoulos-Kalinoglou A, Panoulas VF, et al. New resting energy expenditure prediction equations for patients with rheumatoid arthritis. Rheumatology (Oxford) 2008; 47: 5006.

[14] Devaraj S, Singh U, Jialal I. The evolving role of C-reactive protein in atherothrombosis. Clin Chem 2009; 55: 229-38.

[15] Zhang H, Park Y, Wu J, et al. Role of TNF-alpha in vascular dysfunction. Clin Sci (Lond) 2009; 116: 219-30.

[16] Vanhoutte PM. Say NO to ET. J Auton Nerv Syst 2000; 81: 2717.

[17] Laughlin MH, Roseguini B. Mechanisms for exercise traininginduced increases in skeletal muscle blood flow capacity: differences with interval sprint training versus aerobic endurance training. J Physiol Pharmacol 2008; 59 (Suppl 7): 71-88,

[18] Lerman A, Zeiher AM. Endothelial function: cardiac events. Circulation $2005 ; 111: 363-8$.

[19] Venugopal SK, Devaraj S, Yuhanna I, Shaul P, Jialal I. Demonstration that $\mathrm{C}$-reactive protein decreases eNOS expression and bioactivity in human aortic endothelial cells. Circulation 2002; 106: 1439-41.

[20] Nagaoka T, Kuo L, Ren Y, Yoshida A, Hein TW. C-reactive protein inhibits endothelium-dependent nitric oxide-mediated dilation of retinal arterioles via enhanced superoxide production. Invest Ophthalmol Vis Sci 2008; 49: 2053-60.

[21] Qamirani E, Ren Y, Kuo L, Hein TW. C-reactive protein inhibits endothelium-dependent NO-mediated dilation in coronary arterioles by activating p38 kinase and $\mathrm{NAD}(\mathrm{P}) \mathrm{H}$ oxidase. Arterioscler Thromb Vasc Biol 2005; 25: 995-1001.

[22] Singh U, Devaraj S, Vasquez-Vivar J, Jialal I. C-reactive protein decreases endothelial nitric oxide synthase activity via uncoupling. J Mol Cell Cardiol 2007; 43: 780-91.

[23] Verma S, Li SH, Badiwala MV, et al. Endothelin antagonism and interleukin-6 inhibition attenuate the proatherogenic effects of Creactive protein. Circulation 2002; 105: 1890-6.

[24] Goodwin BL, Pendleton LC, Levy MM, Solomonson LP, Eichler DC. Tumor necrosis factor-alpha reduces argininosuccinate 
synthase expression and nitric oxide production in aortic endothelial cells. Am J Physiol Heart Circ Physiol 2007; 293: H1115-21.

[25] De Palma C, Meacci E, Perrotta C, Bruni P, Clementi E. Endothelial nitric oxide synthase activation by tumor necrosis factor alpha through neutral sphingomyelinase 2, sphingosine kinase 1, and sphingosine 1 phosphate receptors: a novel pathway relevant to the pathophysiology of endothelium. Arterioscler Thromb Vasc Biol 2006; 26: 99-105.

[26] Sorescu D, Griendling KK. Reactive oxygen species, mitochondria, and $\mathrm{NAD}(\mathrm{P}) \mathrm{H}$ oxidases in the development and progression of heart failure. Congest Heart Fail 2002; 8: 132-40.

[27] Gao X, Belmadani S, Picchi A, et al. Tumor necrosis factor-alpha induces endothelial dysfunction in Lepr(db) mice. Circulation 2007; 115: 245-54.

[28] Hurlimann D, Forster A, Noll G, et al. Anti-tumor necrosis factoralpha treatment improves endothelial function in patients with rheumatoid arthritis. Circulation 2002; 106: 2184-7.

[29] Fichtlscherer S, Rossig L, Breuer S, Vasa M, Dimmeler S, Zeiher AM. Tumor necrosis factor antagonism with etanercept improves systemic endothelial vasoreactivity in patients with advanced heart failure. Circulation 2001; 104: 3023-5.

[30] Roman MJ, Moeller E, Davis A, et al. Preclinical carotid atherosclerosis in patients with rheumatoid arthritis. Ann Intern Med 2006; 144: 249-56.

[31] Hannawi S, Marwick TH, Thomas R. Inflammation predicts accelerated brachial arterial wall changes in patients with recent-onset rheumatoid arthritis. Arthritis Res Ther 2009; 11: R51.

[32] Vlachopoulos C, Dima I, Aznaouridis K, et al. Acute systemic inflammation increases arterial stiffness and decreases wave reflections in healthy individuals. Circulation 2005; 112: 2193200 .

[33] Hingorani AD, Cross J, Kharbanda RK, et al. Acute systemic inflammation impairs endothelium-dependent dilatation in humans. Circulation 2000; 102: 994-9.

[34] Wallberg-Jonsson S, Caidahl K, Klintland N, Nyberg G, RantapaaDahlqvist S. Increased arterial stiffness and indication of endothelial dysfunction in long-standing rheumatoid arthritis. Scand J Rheumatol 2008; 37: 1-5.

[35] Dessein PH, Joffe BI, Singh S. Biomarkers of endothelial dysfunction, cardiovascular risk factors and atherosclerosis in rheumatoid arthritis. Arthritis Res Ther 2005; 7: R634-43.

[36] Gonzalez-Gay MA, Gonzalez-Juanatey C, Pineiro A, GarciaPorrua C, Testa A, Llorca J. High-grade C-reactive protein elevation correlates with accelerated atherogenesis in patients with rheumatoid arthritis. J Rheumatol 2005; 32: 1219-23.

[37] Klocke R, Cockcroft JR, Taylor GJ, Hall IR, Blake DR. Arterial stiffness and central blood pressure, as determined by pulse wave analysis, in rheumatoid arthritis. Ann Rheum Dis 2003; 62: 414-8.

[38] Dessein PH, Joffe BI, Veller MG, et al. Traditional and nontraditional cardiovascular risk factors are associated with atherosclerosis in rheumatoid arthritis. J Rheumatol 2005; 32: 435-42.

[39] Vaudo G, Marchesi S, Gerli R, et al. Endothelial dysfunction in young patients with rheumatoid arthritis and low disease activity. Ann Rheum Dis 2004; 63: 31-5.

[40] Del Rincon I, O'Leary DH, Freeman GL, Escalante A. Acceleration of atherosclerosis during the course of rheumatoid arthritis. Atherosclerosis 2007; 195: 354-60.

[41] Veldhuijzen van Zanten JJCS, Kitas GD. Inflammation, carotid intima-media thickness and atherosclerosis in rheumatoid arthritis. Arthritis Res Ther 2008; 10: 102.

[42] Friedman MH, Deters OJ, Bargeron CB, Hutchins GM, Mark FF. Shear-dependent thickening of the human arterial intima. Atherosclerosis 1986; 60: 161-71.

[43] Ku DN, Giddens DP, Phillips DJ, Strandness DE, Jr. Hemodynamics of the normal human carotid bifurcation: in vitro and in vivo studies. Ultrasound Med Biol 1985; 11: 13-26.

[44] Malek AM, Alper SL, Izumo S. Hemodynamic shear stress and its role in atherosclerosis. JAMA 1999; 282: 2035-42.

[45] Cunningham KS, Gotlieb AI. The role of shear stress in the pathogenesis of atherosclerosis. Lab Invest 2005; 85: 9-23.
[46] Hahn BH, Grossman J, Chen W, McMahon M. The pathogenesis of atherosclerosis in autoimmune rheumatic diseases: roles of inflammation and dyslipidemia. J Autoimmun 2007; 28: 69-75.

[47] Wang Q, Zhu X, Xu Q, Ding X, Chen YE, Song Q. Effect of Creactive protein on gene expression in vascular endothelial cells. Am J Physiol Heart Circ Physiol 2005; 288: H1539-45.

[48] Devaraj S, Yun JM, Duncan-Staley C, Jialal I. C-reactive protein induces M-CSF release and macrophage proliferation. J Leukoc Biol 2009; 85: 262-7.

[49] Williams TN, Zhang CX, Game BA, He L, Huang Y. C-reactive protein stimulates MMP-1 expression in U937 histiocytes through Fc[gamma]RII and extracellular signal-regulated kinase pathway: an implication of CRP involvement in plaque destabilization. Arterioscler Thromb Vasc Biol 2004; 24: 61-6.

[50] Nakakuki T, Ito M, Iwasaki H, et al. Rho/Rho-kinase pathway contributes to C-reactive protein-induced plasminogen activator inhibitor-1 expression in endothelial cells. Arterioscler Thromb Vasc Biol 2005; 25: 2088-93.

[51] Singh U, Devaraj S, Jialal I. C-reactive protein decreases tissue plasminogen activator activity in human aortic endothelial cells: evidence that $\mathrm{C}$-reactive protein is a procoagulant. Arterioscler Thromb Vasc Biol 2005; 25: 2216-21.

[52] Prasad K. C-reactive protein increases oxygen radical generation by neutrophils. J Cardiovasc Pharmacol Ther 2004; 9: 203-9.

[53] Landmesser U, Dikalov S, Price SR, et al. Oxidation of tetrahydrobiopterin leads to uncoupling of endothelial cell nitric oxide synthase in hypertension. J Clin Invest 2003; 111: 1201-9.

[54] Landmesser U, Hornig B, Drexler H. Endothelial function: a critical determinant in atherosclerosis? Circulation 2004; 109: II2733.

[55] Wojciak-Stothard B, Entwistle A, Garg R, Ridley AJ. Regulation of TNF-alpha-induced reorganization of the actin cytoskeleton and cell-cell junctions by Rho, Rac, and Cdc42 in human endothelial cells. J Cell Physiol 1998; 176: 150-65.

[56] Iademarco MF, Barks JL, Dean DC. Regulation of vascular cell adhesion molecule- 1 expression by IL-4 and TNF-alpha in cultured endothelial cells. J Clin Invest 1995; 95: 264-71.

[57] Cybulsky MI, Gimbrone MA, Jr. Endothelial expression of a mononuclear leukocyte adhesion molecule during atherogenesis. Science $1991 ; 251$ : 788-91.

[58] Li H, Cybulsky MI, Gimbrone MA, Jr., Libby P. An atherogenic diet rapidly induces VCAM-1, a cytokine-regulatable mononuclear leukocyte adhesion molecule, in rabbit aortic endothelium. Arterioscler Thromb 1993; 13: 197-204.

[59] Ozeren A, Aydin M, Tokac M, et al. Levels of serum IL-1beta, IL2, IL-8 and tumor necrosis factor-alpha in patients with unstable angina pectoris. Mediators Inflamm 2003; 12: 361-5.

[60] Naya M, Tsukamoto T, Morita $\mathrm{K}$, et al. Plasma interleukin-6 and tumor necrosis factor-alpha can predict coronary endothelial dysfunction in hypertensive patients. Hypertens Res 2007; 30: 5418 .

[61] Dixon WG, Symmons DP. What effects might anti-TNFalpha treatment be expected to have on cardiovascular morbidity and mortality in rheumatoid arthritis? A review of the role of TNFalpha in cardiovascular pathophysiology. Ann Rheum Dis 2007; 66: 1132-6.

[62] Avouac J, Allanore Y. Cardiovascular risk in rheumatoid arthritis: effects of anti-TNF drugs. Expert Opin Pharmacother 2008; 9: 1121-8.

[63] Grisar J, Aletaha D, Steiner CW, et al. Depletion of endothelial progenitor cells in the peripheral blood of patients with rheumatoid arthritis. Circulation 2005; 111: 204-11.

[64] Grisar J, Aletaha D, Steiner CW, et al. Endothelial progenitor cells in active rheumatoid arthritis: effects of tumour necrosis factor and glucocorticoid therapy. Ann Rheum Dis 2007; 66: 12848.

[65] Hambrecht R, Walther C, Mobius-Winkler S, et al. Percutaneous coronary angioplasty compared with exercise training in patients with stable coronary artery disease: a randomized trial. Circulation 2004; 109: 1371-8.

[66] Laughlin MH, Armstrong RB. Muscle blood flow during locomotory exercise. Exerc Sport Sci Rev 1985; 13: 95-136. 
[67] Tschakovsky ME, Joyner MJ. Nitric oxide and muscle blood flow in exercise. Appl Physiol Nutr Metab 2008; 33: 151-61.

[68] McAllister RM, Jasperse JL, Laughlin MH. Nonuniform effects of endurance exercise training on vasodilation in rat skeletal muscle. J Appl Physiol 2005; 98: 753-61.

[69] Hambrecht R, Adams V, Erbs S, et al. Regular physical activity improves endothelial function in patients with coronary artery disease by increasing phosphorylation of endothelial nitric oxide synthase. Circulation 2003; 107: 3152-8.

[70] Rehman J, Li J, Parvathaneni L, et al. Exercise acutely increases circulating endothelial progenitor cells and monocyte/macrophage-derived angiogenic cells. J Am Coll Cardiol 2004; 43: 2314-8.

[71] Davis ME, Cai H, McCann L, Fukai T, Harrison DG. Role of c-Src in regulation of endothelial nitric oxide synthase expression during exercise training. Am J Physiol Heart Circ Physiol 2003; 284: H1449-53.

[72] Frangos JA, Eskin SG, McIntire LV, Ives CL. Flow effects on prostacyclin production by cultured human endothelial cells. Science 1985; 227: 1477-9.

[73] Kraus RM, Stallings HW, 3rd, Yeager RC, Gavin TP. Circulating plasma VEGF response to exercise in sedentary and endurancetrained men. J Appl Physiol 2004; 96: 1445-50.

[74] Yang HT, Prior BM, Lloyd PG, et al. Training-induced vascular adaptations to ischemic muscle. J Physiol Pharmacol 2008; 59 (Suppl 7): 57-70.

[75] Hambrecht R, Niebauer J, Marburger C, et al. Various intensities of leisure time physical activity in patients with coronary artery disease: effects on cardiorespiratory fitness and progression of coronary atherosclerotic lesions. J Am Coll Cardiol 1993; 22: 46877.

[76] DeSouza CA, Shapiro LF, Clevenger CM, et al. Regular aerobic exercise prevents and restores age-related declines in endotheliumdependent vasodilation in healthy men. Circulation 2000; 102: 1351-7.

[77] Clarkson P, Montgomery HE, Mullen MJ, et al. Exercise training enhances endothelial function in young men. J Am Coll Cardiol 1999; 33: 1379-85.

[78] Higashi Y, Sasaki S, Sasaki N, et al. Daily aerobic exercise improves reactive hyperemia in patients with essential hypertension. Hypertension 1999; 33: 591-7.

[79] Tuttle JL, Nachreiner RD, Bhuller AS, et al. Shear level influences resistance artery remodeling: wall dimensions, cell density, and eNOS expression. Am J Physiol Heart Circ Physiol 2001; 281: H1380-9.

[80] Malek A, Izumo S. Physiological fluid shear stress causes downregulation of endothelin-1 mRNA in bovine aortic endothelium. Am J Physiol 1992; 263: C389-96.

[81] Himburg HA, Dowd SE, Friedman MH. Frequency-dependent response of the vascular endothelium to pulsatile shear stress. Am J Physiol Heart Circ Physiol 2007; 293: H645-53.

[82] Radak Z, Taylor AW, Ohno H, Goto S. Adaptation to exerciseinduced oxidative stress: from muscle to brain. Exerc Immunol Rev 2001; 7: 90-107.

[83] Seals DR, Desouza CA, Donato AJ, Tanaka H. Habitual exercise and arterial aging. J Appl Physiol 2008; 105: 1323-32.

[84] Adams V, Linke A, Krankel N, et al. Impact of regular physical activity on the $\mathrm{NAD}(\mathrm{P}) \mathrm{H}$ oxidase and angiotensin receptor system in patients with coronary artery disease. Circulation 2005; 111 : 555-62.

[85] Chien S. Mechanotransduction and endothelial cell homeostasis: the wisdom of the cell. Am J Physiol Heart Circ Physiol 2007; 292: H1209-24.

[86] Kasapis C, Thompson PD. The effects of physical activity on serum C-reactive protein and inflammatory markers: a systematic review. J Am Coll Cardiol 2005; 45: 1563-9.

[87] Albert MA, Glynn RJ, Ridker PM. Effect of physical activity on serum C-reactive protein. Am J Cardiol 2004; 93: 221-5.

[88] Geffken DF, Cushman M, Burke GL, Polak JF, Sakkinen PA, Tracy RP. Association between physical activity and markers of inflammation in a healthy elderly population. Am J Epidemiol 2001; 153: 242-50.
[89] Metsios GS, Stavropoulos-Kalinoglou A, Panoulas VF, et al. Association of physical inactivity with increased cardiovascular risk in patients with rheumatoid arthritis. Eur J Cardiovasc Prev Rehabil 2009; 16: 188-94.

[90] Metsios GS, Stavropoulos-Kalinoglou A, Veldhuijzen van Zanten JJCS, et al. Rheumatoid arthritis, cardiovascular disease and physical exercise: a systematic review. Rheumatology (Oxford) 2008; 47: 239-48.

[91] Ford ES. Does exercise reduce inflammation? Physical activity and C-reactive protein among U.S. adults. Epidemiology 2002; 13: 561-8.

[92] McLaughlin T, Abbasi F, Lamendola C, et al. Differentiation between obesity and insulin resistance in the association with $\mathrm{C}$ reactive protein. Circulation 2002; 106: 2908-12.

[93] Abbasi F, Brown BW, Jr., Lamendola C, McLaughlin T, Reaven GM. Relationship between obesity, insulin resistance, and coronary heart disease risk. J Am Coll Cardiol 2002; 40: 937-43.

[94] Taylor C, Rogers G, Goodman C, et al. Hematologic, iron-related, and acute-phase protein responses to sustained strenuous exercise. $\mathrm{J}$ Appl Physiol 1987; 62: 464-9.

[95] Siegel AJ, Stec JJ, Lipinska I, et al. Effect of marathon running on inflammatory and hemostatic markers. Am J Cardiol 2001; 88: 918-20, A9.

[96] Pedersen BK, Akerstrom TC, Nielsen AR, Fischer CP. Role of myokines in exercise and metabolism. J Appl Physiol 2007; 103: 1093-8.

[97] Akerstrom T, Steensberg A, Keller P, Keller C, Penkowa M, Pedersen BK. Exercise induces interleukin- 8 expression in human skeletal muscle. J Physiol 2005; 563: 507-16.

[98] Febbraio MA, Pedersen BK. Muscle-derived interleukin-6: mechanisms for activation and possible biological roles. FASEB J 2002; 16: $1335-47$.

[99] Petersen AM and Pedersen BK. The anti-inflammatory effect of exercise. J Appl Physiol 2005; 98: 1154-62.

[100] Steensberg A, van Hall G, Osada T, Sacchetti M, Saltin B, Klarlund PB. Production of interleukin-6 in contracting human skeletal muscles can account for the exercise-induced increase in plasma interleukin-6. J Physiol 2000; 529 Pt 1: 237-42.

[101] Mathur N, Pedersen BK. Exercise as a mean to control low-grade systemic inflammation. Mediators Inflamm 2008; 2008: 109502.

[102] Febbraio MA, Pedersen BK. Contraction-induced myokine production and release: is skeletal muscle an endocrine organ? Exerc Sport Sci Rev 2005; 33: 114-9.

[103] Schindler R, Mancilla J, Endres S, Ghorbani R, Clark SC, Dinarello CA. Correlations and interactions in the production of interleukin-6 (IL-6), IL-1, and tumor necrosis factor (TNF) in human blood mononuclear cells: IL-6 suppresses IL-1 and TNF. Blood 1990; 75: 40-7.

[104] Mizuhara H, O'Neill E, Seki N, et al. T cell activation-associated hepatic injury: mediation by tumor necrosis factors and protection by interleukin 6. J Exp Med 1994; 179: 1529-37.

[105] Handschin C, Spiegelman BM. The role of exercise and PGC1alpha in inflammation and chronic disease. Nature 2008; 454 : 463-9.

[106] Mootha VK, Lindgren CM, Eriksson KF, et al. PGC-1alpharesponsive genes involved in oxidative phosphorylation are coordinately downregulated in human diabetes. Nat Genet 2003; 34: 26773.

[107] Huss JM, Kopp RP, Kelly DP. Peroxisome proliferator-activated receptor coactivator-1alpha (PGC-1alpha) coactivates the cardiacenriched nuclear receptors estrogen-related receptor-alpha and gamma. Identification of novel leucine-rich interaction motif within PGC-1alpha. J Biol Chem 2002; 277: 40265-74.

[108] Fischer CP, Berntsen A, Perstrup LB, Eskildsen P, Pedersen BK. Plasma levels of interleukin-6 and C-reactive protein are associated with physical inactivity independent of obesity. Scand J Med Sci Sports 2007; 17: 580-7.

[109] Tisi PV, Hulse M, Chulakadabba A, Gosling P, Shearman CP. Exercise training for intermittent claudication: does it adversely affect biochemical markers of the exercise-induced inflammatory response? Eur J Vasc Endovasc Surg 1997; 14: 344-50. 
[110] de Jong Z, Munneke M, Zwinderman AH, et al. Is a long-term high-intensity exercise program effective and safe in patients with rheumatoid arthritis? Results of a randomized controlled trial. Arthritis Rheum 2003; 48: 2415-24.

[111] Noreau L, Martineau H, Roy L, Belzile M. Effects of a modified dance-based exercise on cardiorespiratory fitness, psychological state and health status of persons with rheumatoid arthritis. Am J Phys Med Rehabil 1995; 74: 19-27.
[112] ARC. Guidelines for the management of rheumatoid arthritis: 2002 Update. Arthritis Rheum 2002; 46: 328-46.

[113] Gordon MM, Thomson EA, Madhok R, Capell HA. Can intervention modify adverse lifestyle variables in a rheumatoid population? Results of a pilot study. Ann Rheum Dis 2002; 61: 66-9.

[114] Munneke M, de Jong Z, Zwinderman AH, et al. High intensity exercise or conventional exercise for patients with rheumatoid arthritis? Outcome expectations of patients, rheumatologists, and physiotherapists. Ann Rheum Dis 2004; 63: 804-8.

Received: November 20, 2009

Revised: November 30, 2009

Accepted: December 14, 2009

(C) Metsios et al.; Licensee Bentham Open.

This is an open access article licensed under the terms of the Creative Commons Attribution Non-Commercial License (http://creativecommons.org/licenses/ by-nc/3.0/) which permits unrestricted, non-commercial use, distribution and reproduction in any medium, provided the work is properly cited. 